\title{
¿RAIZALES, PAÑAS, FIFTY, TURCOS O ISLEÑOS?: CONSTRUCCIÓN DE IDENTIDADES EN UN CONTEXTO MULTIÉTNICO ${ }^{1}$
}

\author{
RAIZALES, PAÑAS, FIFTY, TURKS OR ISLANDERS?: CONSTRUCTION OF IDENTITIES IN A \\ MULTIETHNIC CONTEXT
}

*SILVIA ELENA TORRES

Sicóloga. Candidata a Magister en Estudios del Caribe (Universidad Nacional de Colombia). Docente de Infotep. E-mail: set20002@ hotmail.com

Artículo tipo 1 de investigación científica y tecnológica según clasificación Colciencias.

${ }^{1}$ Este articulo, hace parte de los resultados de la investigación denominada "Identidades en contextos multiculturales, estudio de caso de San Andrés Islas" y se realizó en el marco de la Maestría en Estudios del Caribe, de la Universidad Nacional de Colombia, sede Caribe. Contó com recto Caribe. Contó con recursos del fondo de apoyo a la investigación de la Vicerrectoría de Investigaciones de la Universidad Nacional de Colombia.

2 El termino Raizal es la forma en que la poblo isleña nativa ha usado para diferenciar su estatus de grupo tribal y primario de las islas, por encima de los otros grupos étnicos asentados en la misma. Según las investigaciones realizadas por Valencia (2002) al movimiento Son of the Soil, el cual en los años 80 inició las protestas por la marginalidad de la población nativa de los puestos públicos y la actividad económica.

${ }_{3}$ El Puerto Libre es una medida de política económica de exención de impuestos, promulgada por el gobierno del presidente colombiano Rojas Pinillas, como una forma de forta-

lecer la economía de la isla.

lecer la economía de la is trajo como com de turismo aduanero a la isla, que se fortaleció con la construcción del aeropuerto y la transformación cas total de la zona norte de la misma Si bien esta situación generó un "desarrollo ción generó un "desarrollo economico" para que este modelo se llevara a cabo requirió de mucha inversión y mano de obra que se trajo casi que en su mayoría del continente colombiano, que hizo que la población de la isla aumentara de manera desproporcionada.

\section{Por: Silvia Elena Torres*}

Artículo Recibido: Mayo 20 de 2010. Artículo Aprobado: Julio 7de 2010. Páginas: 122-143

\section{RESUMEN}

Colombia reconoce y protege constitucionalmente la diversidad étnica y cultural de la Nación, pese a ello, a través de este artículo se analiza cómo en un contexto multiétnico, como en el caso de la Isla de San Andrés, el reconocimiento de la etnia Raizal ${ }^{2}$ aunque se considere válido, conlleva a situaciones problemáticas, tales como la tendencia a resaltar los valores de la cultura raizal por encima de los otros grupos étnicos que cohabitan en la isla, en la medida en que invisibiliza las otras formas de ser isleños, tales como; los isleños hijos de los continentales y extranjeros nacidos en la isla, producto de las migraciones de las que ha sido objeto la isla a partir de la declaratoria del Puerto Libre ${ }^{3}$ o de las uniones interétnicas, la mayoría de ellas entre población raizal y otros grupos culturales, que se dieron como consecuencia de este proceso migratorio.

Palabras clave: Construcción de identidades, etnicidad, multiétnico, Caribe insular colombiano.

\section{ABSTRACT}

Colombia recognizes and constitutionally protects the ethnic and cultural diversity of the Nation. However, this article analyzes how in a multiethnic context, as in the case of San Andres Island, the recognition of the Raizal ethnic group although considered valid, leads to problematic situation, such as, the tendency to stand out the values of the raizal culture over other ethnic groups that live in the island, to extent the invisible ways of being an islander, such as Islander children of continentals and foreigners born in the island as a product of the migrations that the island has experienced since the declaration of the Free Port or the interethnic unions, the majority of them are between the raizal population and other cultural groups, which occurred as consequence of this migratory process.

Keywords: Construction of identity, ethnicity, multiethnic, Insular Caribbean of Colombia.

\section{Introducción}

F 1 archipiélago de San Andrés, Providencia y Santa Catalina, al cual pertenece la isla de San Andrés, está ubicado en el suroccidente del mar Caribe, sobre la dorsal de Jamaica, una cordillera submarina, a solo 180 km. de la costa de Mosquitía en Nicaragua y a más de 800 km. 


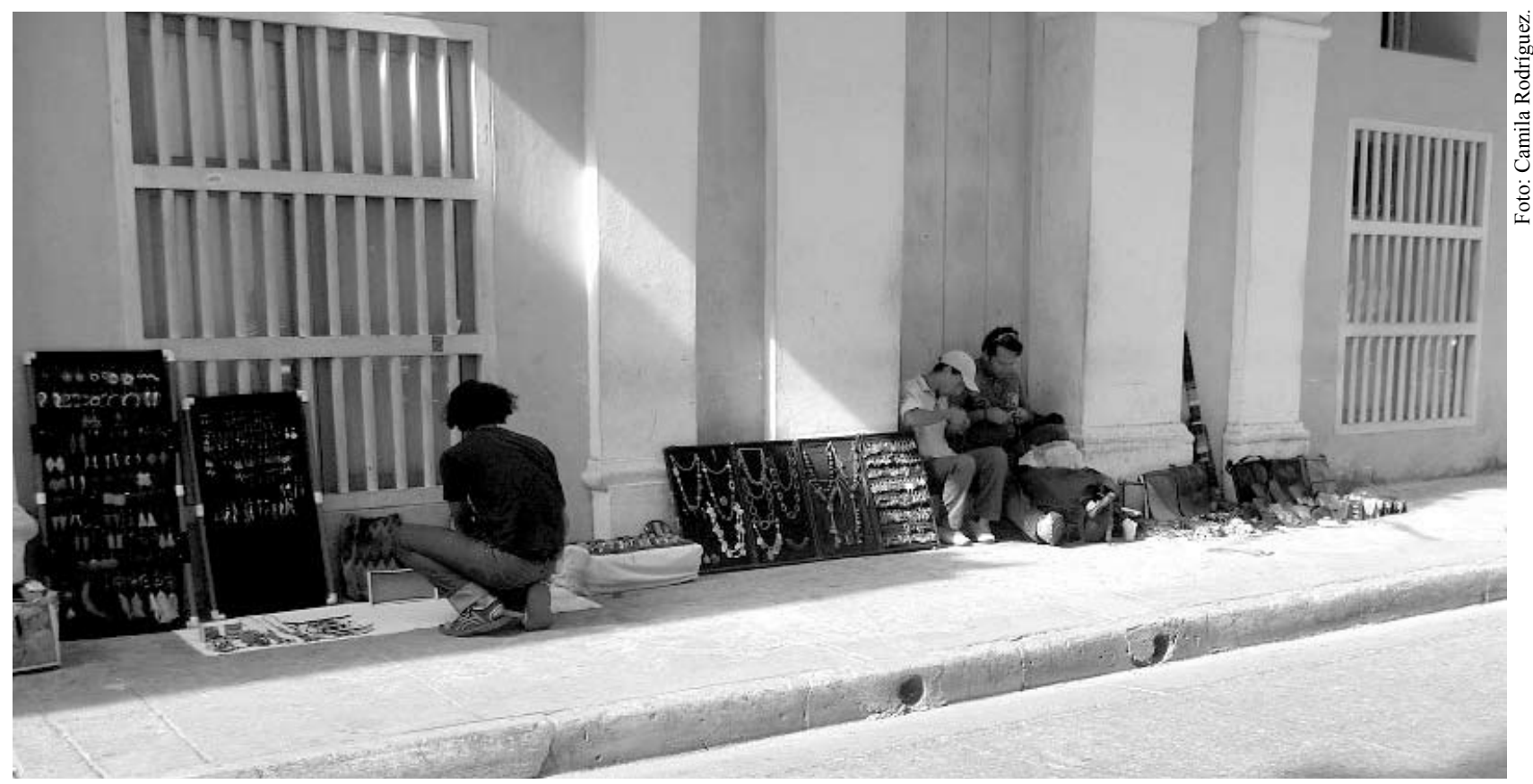

Ambulantes de artesanías. Cartagena 2011.

del borde continental colombiano, país al que pertenecen. Está conformado por tres islas mayores habitadas (San Andrés, Providencia y Santa Catalina) y numerosos islotes, cayos, bancos y bajos, la mayoría de origen coralino (Parsons, 1985:13). En el año 2000, debido a las condiciones especiales ambientales y culturales del Archipiélago y a las oportunidades que ofrece este para conciliar las relaciones hombre-entorno natural y promover modelos de desarrollo sostenible, el programa Hombre y Biósfera, de la UNESCO, declara al departamento Reserva de la Biósfera, bajo el nombre de "Reserva de la Biósfera Seaflower", en honor a la embarcación en la que llegaron los puritanos en 1631, primeros colonizadores de las islas (Newton, 1985:214).

Por su parte, la isla de San Andrés tiene $27 \mathrm{Km}^{2}$, es la capital del Departamento Archipiélago de San Andrés, Providencia y Santa Catalina, y se caracteriza por ser "una isla de origen coralino, compuesta por caliza coralina blanca, depositada en una base volcánica" (Ratter, 2001:78). Según los datos arrojados en el censo de 2005, la población de ese año era de aproximadamente 55.426 habitantes, dentro de los cuales se cuentan los isleños raizales, los isleños nativos, y los migrantes continentales y extranjeros, con una "proyección de crecimiento para el año 2010 de 68.331, de los cuales el 50.99\% son mujeres y el 49.01\% son hombres" (Dane, 2009). También en San Andrés se concentra el mayor porcentaje de las actividades económicas del archipiélago, la mayoría basadas en el turismo y el comercio. 
${ }^{4} \mathrm{Al}$ respecto se recomienda revisar los artículos 7 y 310 de la constitución política de Colombia, al igual que el artículo transitorio 42, que son los que promulgan en el marco de la diversidad y protección étnica del país el estatus especial de Archipiélago y mencionan la necesidad de crear leyes especiales que protejan a territorio y su población nativa Raizal. Es en el marco de estas normas constitucionales que después surge el decreto ley 2760 que crea la Oficina de Control de la Circulación y Residencia OCCRE y la ley 47 de 1993 que se considera una ley especial tanto para la organización administrativa, como en materia fiscal y de protección cultural para el Archipiélago. Tanto la ley que crea la OCCRE como la ley 47 cuentan con total respaldo de la corte constitucional según lo expresado en sus sentencias posteriores y se consideran normas que están al mismo nivel de las de tipo constitucional.
La isla de San Andrés, al igual que todo el Archipiélago, pertenece al Estado colombiano y si bien su población nativa raizal se consideran colombianos, debido a sus condiciones geográficas, históricas y culturales que constituyeron a la sociedad isleña nativa, asentada desde la época de la colonia y que se desarrollo casi que aisladamente del resto de la población colombiana hasta 1953 con la declaratoria del Puerto Libre, con una tipología de base angloafrocaribeña y que a partir de lo pronunciado en la Constitución de 1991, hacen parte de los grupos considerados minorías étnicas en el país y cuentan con una normatividad especial tanto para la población como para el territorio insular".

En la isla cohabitan con los raizales, otros grupos étnicos que llegaron en su mayoría después de la declaratoria del Puerto Libre. Estos grupos son llamados popularmente como "pañas" y "turcos". Los primros son los colombianos continentales, hispanos hablantes, que provienen en su mayoría de las distintas zonas del Caribe continental colombiano y del departamento de Antioquia. Se distinguen porque ocupan casi toda la zona norte y el centro de la isla, y si bien todos los hispanos hablantes se denominan "pañas", dentro de este grupo hay diferencias significativas de estratificación, ocupación económica y condiciones sociales en la isla.

Por ejemplo, en el territorio insular, la colonia paisa ocupa un lugar importante en el sector turístico y comercial de la isla y están residenciados en barrios considerados de estratos altos, mientras que los migrantes y descendientes de la zona Caribe continental colombiana, en su mayoría se dedican a los oficios varios y se consideran la mano de obra de la hotelería y el turismo en general. Otra característica interesante de este segundo grupo de "pañas", es que viven mayoritariamente en barrios no legalizados, es decir, que no cumplen con las especificaciones de planeación departamental y es en estos barrios en donde se genera un alto porcentaje de los casos de violencia social que se reporta en la isla.

Por su lado se conoce como "turcos", a los sirios- libaneses, que profesan en su mayoría la religión musulmana y su lengua materna es el árabe. Algunos de estos, llegaron directamente de sus lugares de origen, otros ya estaban asentados en la región Caribe colombiana y su característica principal es que la mayoría del comercio está bajo su dominio y poco se involucran de manera directa en los asuntos administrativos y políticos de la isla. 
Un cuarto grupo que si bien no es étnico, si aparece como categoría social, lo conforman los denominados fifty- fifty o half and half. Se asocia a este grupo a todos los isleños o sus descendientes que son producto de las distintas mezclas entre la comunidad nativa raizal y los demás grupos culturales que cohabitan en la isla o de uniones con extranjeros (entre los que se pueden destacar centroamericanos, especialmente hondureños y nicaragüenses, y europeos principalmente italianos y alemanes). A pesar de que este grupo es el resultado de las uniones interétnicas, la mayoría se asumen culturalmente como raizales por el concepto de ancestralidad, aunque no hablen el idioma de la etnia o no vivan en el territorio insular.

Adicional a los grupos antes mencionados, también se encuentran en las islas otras colonias, que si bien tienen menor grado de población, no son menos importantes. Este es el caso de las familias judías, que tienen significativa representatividad en el comercio y muchos se encuentran asentados desde hace años en la isla y han aportado a su desarrollo. Otro grupo presente es el italiano, que es más reciente pero se ha incorporado en las actividades comerciales y del sector turístico con relativa representatividad. Por último vale la pena destacar la presencia argentina en la isla, aunque de pocas familias, han logrado tener una participación económica importante en la sociedad isleña.

Por la composición poblacional de la isla, es que se observa que, a pesar de la política proteccionista del Gobierno nacional, expresada en la normatividad especial, los efectos poblacionales ocasionados por la migración desmedida ocurrida por más de 50 años, desde 1953 fecha que inicia el Puerto Libre hasta 1991 cuando entra en vigencia la Oficina de Control de Circulación y Residencia OCCRE, ha traído como consecuencia un nuevo orden social y nuevas expresiones culturales que han desplazado las formas preexistentes en la isla anteriores a este periodo, incluida su población nativa Raizal.

Desde 1999 se han venido presentando marchas de algunos representantes de la comunidad raizal, entre los que se encuentran líderes religiosos de las iglesias Bautistas y representantes de organizaciones civiles ${ }^{5}$, como protesta por la situación de detrimento de su cultura y de las condiciones de la isla en general. Estas marchas y protestas que según algunos pobladores han tenido poca transcendencia, han logrado, sin embargo, dos hechos significativos en la historia insular. El primero de ellos, fue la proclamación de la independencia y la constitución de un estado insular, en una marcha realizada en el 2007,

${ }^{5}$ La revista Cuadernos del Caribe 4 de la Sede Caribe de la Universidad Nacional de Colombia, denominada "Textos y testimonios del archipiélago; crisis y convivencia en un territorio Insular" está dedicada a las entrevistas realizadas a representantes de los distintos grupos culturales de la comunidad isleña, entre los cuales se encuentran varios líderes Raizales que participaron en la marcha de 1999. 
${ }^{6}$ Según Guevara (2005) el grupo AMEN-SD, surgió en el año de 1999 producto de la primera gran marcha de la población raizal realizada en ese año y desde entonces se ha consolidado como una opción de autodeterminación de esta población. En la marcha de 2007 este grupo manifiesta su tendencia separatista cuando en separatista, cuandoen esta, proclama la independenci de las islas de la nación colombiana y crean el Estado Raizal para las Islas. Para mayor información se puede consultar el texto "185 años de colonialismo interno (1822-2007), colgado en la página web del grupo: www.amen-sd.org.

${ }^{7}$ En los datos del CENSO de 2005, se puede obtener una tabla que muestra el lugar de nacimiento de las personas que habitan en la isla, y esta tabla señala más del 56\% de la poblacion isleña es nacida aquí. Estos datos pueden ser corroboraRegistro de población y vivienda censo de 2005 En: http://www.dane.gov.co También en la página web del Departamento Archipiélago de San Andrés, Providencia y Santa Catalina, en el link de la Secretaría de Salud, se pueden encontrar los datos estadísticos sobre el crecimiento poblacional y la natalidad desde 1985 de la isla y su proyección futura hasta el 2011, en la página web: www.gobernacionsai. gov.co donde miembros del grupo separatista "The Archipélago Movement for Ethnic Native Self Determination- AMEN-SD" ${ }^{6}$ bajan la bandera colombiana e izan la bandera de su nuevo estado. Como consecuencia de este hecho, en este mismo año, el presidente de la República Andrés Pastrana, expide el decreto 2548, que tenía como objetivo crear una comisión para revisar la normatividad especial del Archipiélago y de la población raizal con el objetivo principal de crear el estatuto especial para el Departamento y los raizales, pero hasta el día de hoy solo se ha avanzado en la oficialización de la consulta previa. El segundo acontecimiento, y aunque no se le relacione directamente con esta situación, son las políticas intervencionistas del Gobierno Nacional que nombró al Hospital Departamental "Amor de Patria" y que realizó por primera vez desde la conformación del Estado colombiano, la principal ceremonia nacional de celebración del aniversario del 20 de julio del año 2008 en la isla.

Si estas situaciones están ocurriendo a nivel político, la situación en el plano de lo demográfico está todavía más acentuada, sobre todo por el tema de la llamada "sobrepoblación", a la cual se le atribuyen las causas de problemáticas sociales. Ante esta situación, las respuestas que más se escuchan es que todavía están llegando más migrantes a las islas, que no tienen posibilidades de tener una mediana calidad de vida y que acentúan los problemas ya existentes. Sin embargo, ante esta problemática, debe considerarse que con la entrada en vigencia de la OCCRE y según los datos del Censo de 2005, más que aumento de la migración lo que ha aumentado es la emigración, lo que indica que San Andrés es un sitio expulsor de población, pero además también señala que en la isla desde las últimas décadas se está produciendo un innegable aumento de la natalidad ${ }^{7}$.

La natalidad en San Andrés se considera un factor clave para la compresión de las problemáticas y conflictos en la isla, no solo porque aumenta la población, sino porque cada vez son más los nacimientos de hijos de migrantes que llegaron después de la declaratoria del Puerto Libre. Estos nacidos en la isla, que son productos de diásporas, no mayores a 50 o 60 años, son los que están configurando una nueva población isleña, y es justamente donde la situación toma dimensiones mucho más complejas y difíciles de abordar. Al respecto hay posturas radicales que consideran que estos isleños son del lugar de donde vienen sus padres, porque la isla no tiene la capacidad de cargar tantas personas. Negándoles a estos las posibilidades de auto identificarse como isleños y la opción de construir un proyecto de vida en la isla. 
Además de la natalidad, y el conflicto identitario que en esta subyace ${ }^{8}$, el problema poblacional se acentúa por el factor de apropiación territorial. Si bien es cierto que en la isla todavía existen grandes porciones de tierra pertenecientes a familias "raizales", también hay otro gran porcentaje de tierras ocupadas por los migrantes continentales, sirio-libaneses, judíos y sus descendientes. Por lo anterior, ya no se podría decir que solo los "raizales" son los únicos con derechos territoriales en la isla, a pesar de que legalmente, según la ley 47 de 1993, es de esta manera.

Teniendo en cuenta, por un lado las disposiciones normativas de protección para las islas y su población nativa raizal, pero que estas se dan por otro lado, en un contexto en que además de estos, cohabitan en la islas otros grupos culturales o étnicos, producto de un proceso migratorio que duró más de 50 años, es que se considera el problema de la identidad isleña relevante, en la medida en que se plantea la reflexión sobre quiénes son los isleños y qué factores son los que determinan esa identidad. Como una forma de comprender y analizar esta situación se planteó esta investigación, la cual pretendía responder a la siguiente pregunta de investigación ¿Cómo y bajo qué condiciones se construyen las identidades socioculturales en un contexto multiétnico, producto de migraciones generadas a partir de la declaratoria del Puerto Libre en San Andrés Islas?

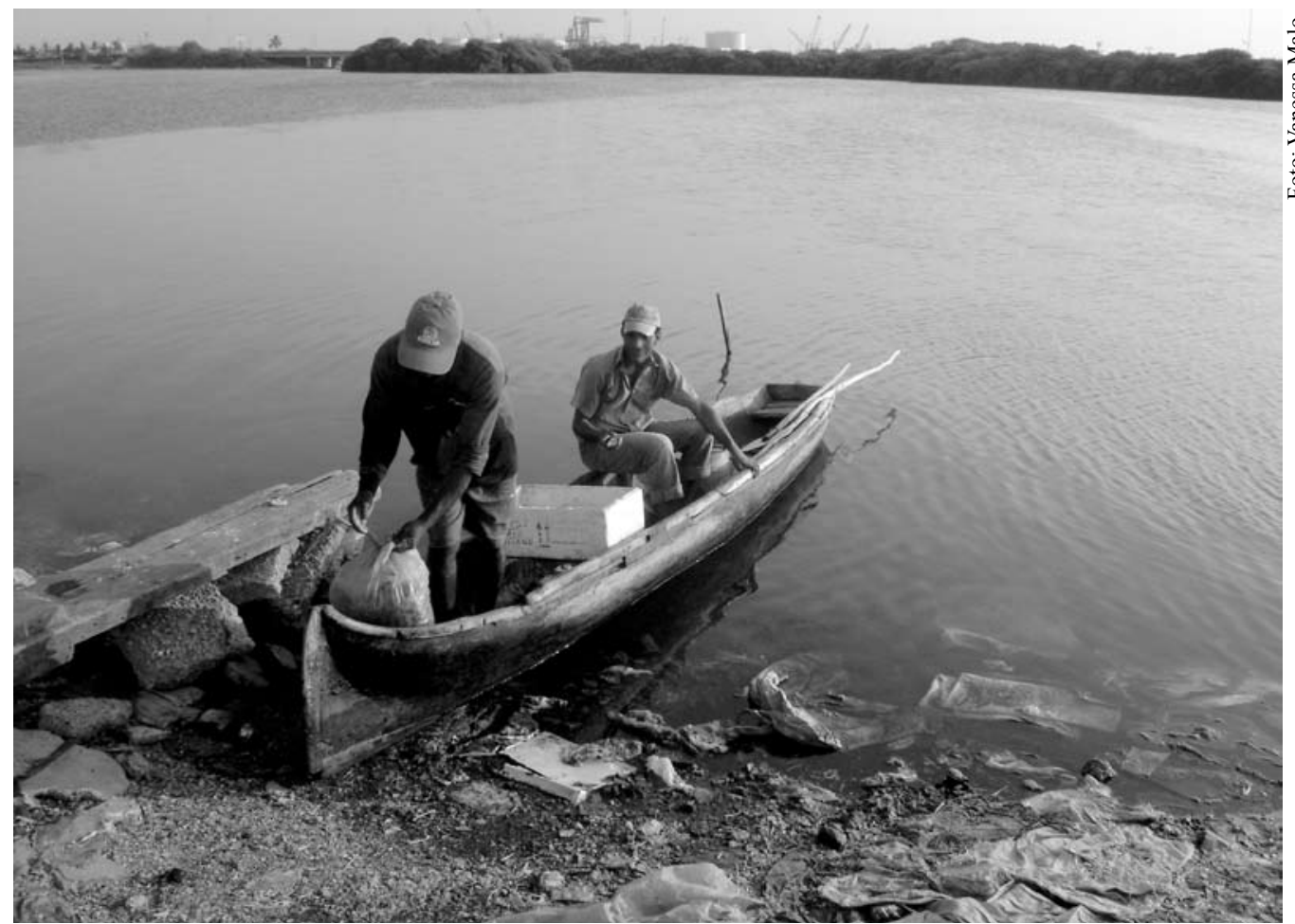

Laguna de Bazurto. Cartagena 2011.
${ }^{8}$ En el último consejo comunitario realizado por el Presidente Uribe en el año 2009 en la isla de San Andrés, una mujer Raizal de apellido Huffington le preguntó al presidente lo siguiente ¿De donde son los hijos de Cartageneros que nacen en la isla de San Andrés? El presidente no contestó. Por lo que la señora le pide la presidente que revise la al presidente que revise la normatividad de la OCCRE, ya que según ella en este órgano están discriminando a esta población. 
9 El principal concepto que se retoma en esta inves-
tigación del autor, es la diferenciación que hace sobre las viejas etnicidades y nuevas etnicidades, en donde reconoce la importancia del autoreconocimiento y de ocupar una posición desde la cual el sujeto habla y se define, siendo esto un punto que resalta de la vieja etnicidad. Sin embargo, inmediatamente llama la atención de los peligros de que ese lugar desde el que se habla se constituya en una única manera de comprender las identidades, sobre todo lo referido a la identidad cultural, debido a que esta visión deja de lado la importancia que tienen las nuevas formas de construcciones identitarias que se dan a través de procesos como las migraciones, las diásporas y los relaciones de poder que se establecen en las relaciones sociales, dentro de las cuales las identidades se han convertido en el discurso desde donde se habla para lesde donde se habla para lograr posicionamiento y
movilización social. Por otro lado, considera que la nueva etnicidad "Es una nueva concepción de nuestras identidades porque no ha perdido el asidero del lugar y el suelo desde $l$ que podemos hablar, pero no estamos ya mablar pero no estamos ya más contenidos dentro de ese lugar como una esencia. Da cuenta de una más amplia variedad de experiencias. Forma parte de la enorme relativización cultural del globo entero que es históricamente alcanzad es historicanente alcanzada horriblemente como ha sido en parte en el Siglo $X X^{\prime \prime}$. En esta deconstrucción de la etnicidad, Hall considera que "todo el mundo tiene una etnicidad porque todo el mundo viene de una tradición cultural, un contexto cultural e histórico; esta es la fuente de la producción de sí mismos, por lo que todos posen una etnicidad".
Como una forma de dar respuesta a este interrogante, en el desarrollo de la investigación, se realizo un análisis histórico de la isla, un análisis de discursos oficiales y no oficiales en torno a las identidades, además de un análisis biográfico a partir de la documentación de siete historias de vida a jóvenes isleños pertenecientes a los distintos grupos étnicos que cohabitan en la isla.

\section{Algunos aspectos teóricos y metodológicos a resaltar.}

Para el desarrollo de la investigación, se trabajó como enfoque teórico la perspectiva transdiciplinaria de los estudios caribeños planteada por Sandner (2003), retomando los postulados de Mintz (1971:17-46) y Moreno (1996, 1999), sobre cómo se ha ido configurado el espacio regional Caribe, a través de la historia, la geopolítica y los sistemas económicos, lo cual ha originado en las sociedades caribeñas una tipología que las caracteriza como un área sociocultural, donde su principal característica es la tendencia a procesos de mestizajes e hibridación y a la diversidad cultural. Para el estudio de las identidades se trabajó inicialmente con los planteamientos teóricos de Hall (1985:87-95) ${ }^{9}$, sobre el concepto de identidad cultural y étnica, y las sugerencias metodológicas realizadas por Restrepo (2007). Pero también se retomaron posturas teóricas que tratan sobre el estudio de las relaciones interétnicas tales como, Bart (1969) y Lonzsoncy (1997: 253-278), entre otros.

En los aspectos metodológicos, la investigación se desarrolló desde el enfoque cualitativo, constituyéndose esto en un estudio de tipología fenomenológica, que buscaba comprender cómo se constituyen en un determinado momento y bajo unas condiciones específicas, las identidades en un territorio construido por diversidades étnicas, quienes a su vez conforman una sociedad caribeña mestiza y compleja. Los métodos con los cuales se trabajaron fueron, el análisis de textos, el análisis discursivo y el análisis biográfico a través de la realización de historias de vida a isleños, entre 19 y 35 años, y que se caracterizan por pertenecer a los distintos grupos culturales que cohabitan en la isla.

El análisis de texto se realizó a través de la revisión de documentos oficiales y producto de investigaciones sobre la historia de las islas y sus dinámicas de poblamiento. Esta revisión, permitió la comprensión de la periodización de la historiografía de la isla y la realización del análisis de cómo algunos eventos se consideran significativos en la explicación de la composición y organización actual de la isla. En el análisis discursivo, a través de la lectura de documentos 
oficiales y no oficiales, revisión de libros y la realización de entrevistas, se analizaron los discursos del gobierno nacional y local, también los discursos desde la representación política y las investigaciones y estudios académicos, lo que permitió determinar el estado del arte y de la discusión identitaria en la isla. Para contrarrestar el análisis de estos discursos, también se analizó el de las organizaciones raizales y algunos actores sociales que pertenecen a los distintos grupos culturales que habitan el territorio insular.

Para finalizar, el análisis biográfico, se realizó a través de la documentación de las historias de vida de siete jóvenes, por medio de entrevistas a profundidad y la observación; de los cuales tres son raizales, una raizal de práctica religiosa protestante y otra católica, también se documento la historia de un raizal de descendencia china ${ }^{10}$. Las otras historias de vida correspondieron a una joven categorizada como perteneciente al grupo de los fifty-fifty, a un joven isleño de origen libanés y dos jóvenes de padres "pañas", pero cuyas familias provienen una de la zona andina y la otra de la costa Caribe colombiana.

En este sentido, las historias de vida se realizaron como una forma de contar y de entender una historia social. Estas según el módulo de investigación cualitativa del ICFES, desarrollado por Sandoval, se constituyen en una importante herramienta para el desarrollo de la historia social de carácter crítico. Logran un acercamiento a la realidad social que estos sujetos representan. Según el texto este método ayuda a "la reflexión de la estructura, dinámica y evolución y de las relaciones sociales que subyacen a la constitución como sujetos individuales o colectivos, de los miembros de los grupos en cuestión" (1996:92).

\section{Resultados encontrados}

Los resultados de la investigación se dividen en tres títulos, de acuerdo a la metodología empleada. El primero de ellos, es producto del análisis histórico, donde se resaltan algunos acontecimientos como significativos para comprender la situación sociocultural actual de la isla, el segundo resultado, da cuenta del análisis discursivo que se realizó en torno a las posturas oficiales y no oficiales que existen en torno a las identidades socioculturales en la isla. Y por último, el tercer resultado fue el que se obtuvo del análisis biográfico de las historias de vida documentada. A continuación se destacan los aspectos más significativos de cada uno de estos.

${ }^{10} \mathrm{El}$ componente chino poco se menciona dentro de las características del grupo raizal. Sin embargo este grupo que está representado en un número significativo de familias que conservan el apellido y algunos rasgos de la descendencia asiático, son actores importantes dentro de la sociedad isleña. En re te documento no se señalan de manera aparte por considerarlos dentro del grupo étnico raizal, ya que ellos han asumido esta condición. 


\section{San Andrés Isla: Entre las dinámicas del Caribe occidental y la pertenencia a la nación colombiana.}

De acuerdo a lo planteado por Sandner (op. cit.), el Archipiélago, pero en especial la isla de San Andrés, siempre ha estado inmersa en las dinámicas geopolíticas del Caribe occidental, con estrechos vínculos con el istmo centroamericano, tanto en los aspectos socioculturales, como en los conflictos por los límites fronterizos, como las pretensiones territoriales tanto de Nicaragua como de Colombia. En los aspectos socioculturales, se destaca la constante movilidad de la población de las islas, en épocas tempranas a sitios como Panamá, Jamaica, la costa de Mosquitía y Cartagena, entre otros. También se dieron movimientos a la inversa, de estos sitios a las islas, por lo que la cultura de las islas, se ha alimentado y construido por la gran influencia de estos sitios al entorno insular.

En el aspecto geopolítico, desde el mismo momento de la primera colonización puritana en 1631, se dio una confrontación directa entre los imperios inglés y el español por el dominio y control de las islas. Estas confrontaciones de ida y vuelta, resultó en un tratado histórico (anexo al tratado de Versalles); se podría incluso decir que la isla de facto era inglesa, pero jurídicamente era española. Este antecedente y las posteriores confrontaciones que se dieron por la jurisdicción que administraría las islas, también son significativas para comprender las reclamaciones actuales de si estas islas son centroamericanas o suramericanas ${ }^{11}$.

Si en ese momento histórico las islas hubiesen seguido bajo la jurisdicción de Guatemala, tal vez en estos momentos las islas en una evaluación natural, estarían en disputa o pertenecería a Nicaragua u otro país del istmo. Sin embargo, la orden real de 1803 selló la fortuna de las islas al Virreinato de la Nueva Granada, y desde esta orden real, es donde se da el fundamento para la pertenencia de las islas a la actual Colombia, la cual fue ratificada por una anexión voluntaria de los isleños a este país en 1821 (Uribe, 1986:23) y que fué ratificado por un comité de notables, llevado a cabo después de la

11 Al respecto, Gaviria (1984), realiza una publicación denominada "Complemento de la historia de Colombia: Nuestro Archipiélago de San Andrés y la costa Mosquitía Colom biana" donde se dedica a explicar como con la proclamación de la cédula real clamación de la cédula real siempre han pertenecido a Colombia. Plaza y Janes. Academia colombiana de Historia, Bogotá separación de Panamá hacia 1903 (Vollmer, 1997:64).

Si la historia solo se suscribiera a los tratados jurídicos y no a los acontecimientos cotidianos y a los intereses estratégicos de las naciones o estados, San Andrés en su condición de periferia nacional hubiese seguido con un desarrollo tal vez autónomo y un poco marginado de la nación a la cual 
pertenece. Sin embargo, los intereses políticos y comerciales norteamericanos en la zona del istmo y del Caribe, influenciaron de manera directa a las islas, haciendo en primera medida que a través de estos vínculos la población isleña desarrollara unas prácticas culturales, políticas, económicas, religiosas y hasta deportivas que obedecían en gran medida a prácticas de la población afroamericana del sur de Estados Unidos y algunas zonas del Caribe, como Jamaica y Trinidad, Islas Caimán, entre otras.

Estas relaciones comerciales y culturales de la isla, que incluso trajo como migrantes chinos a las islas, se vieron mermadas por los efectos de la separación de Panamá de Colombia y el decaimiento de la plantación cocotera; las islas comenzaron a volverse más colombianas y a fortalecer sus vínculos con el país. Este fortalecimiento de la presencia del estado en las islas, desemboca en el tratado Esguerra- Bárcenas y en la instauración de la misión capuchina en las islas (Clemente, 1994:331-372).

A pesar de lo anterior, los textos históricos y la literatura local, señalan como las islas no perdieron sus fuertes vínculos con el istmo centroamericano, en especial con Panamá y con las islas de Bluefields y Corn Island. En la novela de Hazel Robinson "Sail Ahoy", la goleta "Endurece" en sus rutas comerciales contaba con trayectos desde Providencia hacia San Andrés, Colon y Cartagena, donde dejaba productos agrícolas, especialmente naranjas. En este circuito comercial, e incluso cultural, la costa Caribe colombiana hacia parte de la dinámica en ese momento de las islas, solo que la presencia física de la población continental en la isla era mínima, habitaban en la isla solamente algunos comerciantes, funcionarios públicos y los misioneros (Vollmer, op. cit.).

Una de las hipótesis a las que se llega, después de analizar ese momento histórico de las islas, es que para la población isleña de la época, fue más conveniente pertenecer a Colombia, que a Estados Unidos o a cualquier otra nación centroamericana, debido a que la lejanía del estado ausente, pero que les daba cierta protección, permitía un desarrollo social, cultural, económico e incluso político propio a los isleños, lo cual les garantizaba cierta autonomía y autogobierno.

Sin embargo, esta situación comenzó a disminuir con la cada vez más intervención política del gobierno central, a través de las acciones de evangelización, catolización y educación a la población insular de la Iglesia

Palubra No. 11. Septiembre de 2009 - Agosto de 2010 


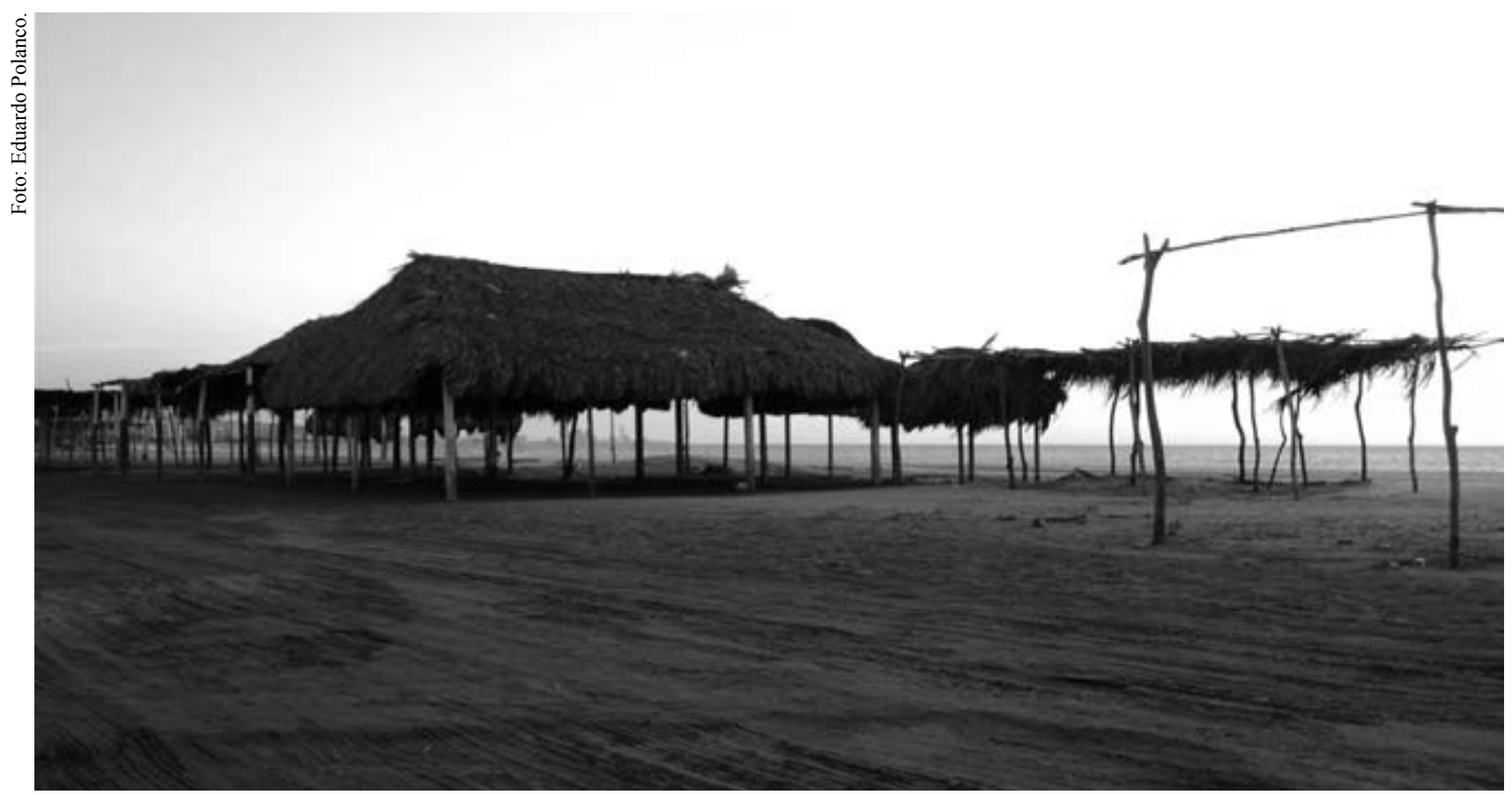

Puestos de ventas. Cartagena 2011.

${ }^{12}$ Hay incluso entre representantes de la población nativa raizal, quienes se destacan como Dulph Mitchell del grupo Amen- SD y Enrique Pusey, entre otros que exponen que en esta época inicio la "colonización de las islas" por parte del estado colombiano. Lo del estado colombiano. Lo anterior, lo exponen en los textos: Análisis de los mo-
tivos para las exigencias de Autodeterminación del Pueblo Raizal ante los Organismos Internacionales $\mathrm{OAS}$ y $\mathrm{ONU}$ Conferencia presentada en el marco del seminario sobre normatividar étnica Septiembre de 2010. (DocuSeptiembre de 2010 . (Docu-
mento inédito de Mitchell) y "Los Sucesivos Reclamos de Nicaragua" (2003) de Pusey, en: Revista Islander, Bilingual Magazine, Núm. 14. San Andrés.

13 El modelo económico del monocultivo de coco para su exportación a Estados Unidos, fue el modelo vigente en la isla de San Andrés desde finales de 1850 hasta 1929 aproximadamente, cuando una plaga acaba con los cultivos $y$ la una baja de precios en da una baja de precios en el mercado. Ver los trabajos realizados por Meisel sobre el modelo económico de la isla de San Andrés, realizados en el 2003 y el 2009. católica, en su primer momento, y después por intermediación de la intendencia y de las otras instituciones nacionales con presencia en la isla. Este conflicto, entre nación y comunidad isleña, y que algunos representantes de la comunidad denominan "la colonización de las islas por parte del estado colombiano" 12 , se cree es muy anterior a la declaratoria del Puerto Libre, pero que poco se ha estudiado, porque se presume hubo mucha responsabilidad de personajes prestantes isleños en la pérdida de territorio y gobernabilidad por parte de estos con respecto a la nación colombiana.

Lo anterior, sumado a la caída del modelo económico de exportación del monocultivo cocotero a Estados Unidos ${ }^{13}$, que trajo como consecuencia una fuerte crisis económica a la isla y la emigración de muchos isleños a sitios como Colon y Bocas del Toro en Panamá y otros sitios del Caribe y el continente colombiano, fue propicio para que se diera una intervención de tipo económica como fue la declaratoria del Puerto Libre por parte del General Rojas Pinillas en 1953, a este proceso Meisel le denomina en sus investigaciones "la continentalización de las islas" (Meisel, 2003) en la medida que a partir de allí la isla quedan completamente integradas a la dinámica nacional.

Otro factor que pudo haber influido en la fácil apropiación de tierras y de dominación económica, que desplazó significativamente la participación de la población raizal, por parte del migrante continental colombiano y extranjero, 
podría tener su explicación en la división y organización social de la población isleña de la época, que según Price estaba divida claramente en "clase alta y clase baja"14. Mientras que los de clase baja se acercaban más al gobierno nacional en busca de oportunidades laborales y de educación, a muchos de estos se les denominaba "catolics job"15, los de clase baja preferían seguir con su instrucción y vínculos con Norteamérica y la iglesia protestante (Price, 1954:33).

Es en este sentido que se considera que estando la población local dividida en intereses y proyección social, se dieron todas las condiciones para que a través de la expropiación y la compra no controlada o el subarriendo de tierras ${ }^{16}$, fuera relativamente fácil la apropiación del espacio insular por parte de los nuevos migrantes, quienes con el tiempo construyeron nuevas territorialidades y formas de organización espacial en la isla que transformaron de manera radical el paisaje y la división social de la población sanandresana (González, 2003). En este nuevo orden social se dió otra forma de división de clases sociales, donde los extranjeros y los continentales andinos, bogotanos y paisas, comenzaron a constituirse en la élite de la isla, junto con algunos isleños raizales y fifty- fifty que también controlaban la economía y la política de la isla.

En esta nueva estructura social, también se desarrolla una clase media, constituida por muchos migrantes andinos y costeños, e incluso gran parte de la población raizal, quienes eran empleados públicos, profesores o empleados del sector privado ubicados en puestos ejecutivos, que la isla le ofrecía unas buenas condiciones de vida.

Por otro lado, la tradicional clase baja en la isla, se transforma igual que la clase alta, pero con dimensiones diametralmente opuestas, debido a que la primera tenía por lo general sus tierras o parcelas; pero con las migraciones comenzaron a llegar migrantes, en su mayoría provenientes de Caribe continental colombiano, que no tenían donde vivir y que se vieron en la necesidad de alquilar algunos predios a isleños raizales, donde se asentaban varios grupos de familias por predio y construían asentamientos de una precariedad casi marginal. En estas condiciones, la nueva clase baja de la isla, la constituyen en su mayoría migrantes que de manera precaria y con muchas necesidades básicas insatisfechas y sin tierras sobrevivieron y sobreviven con dificultad a la vida insular.
${ }^{14}$ En 1954, poco después de la declaratoria del Puerto Libre, Price realiza un estudio etnográfico en la isla el cual describe que una de las características sociales de la población isleña es que estaba dividida en "clase alta y clase baja, a pesar de la tendencia al igualitarismo que se expresaba en la frase "nadie es mejor que los demás". Sin embargo, la clases sociales estaban reflejadas en "la situación económica y conducta social"

${ }^{15}$ El término "catolic jobs" se usaba para referirse entre la población isleña a aquellos que para acceder a beneficios de la iglesia católica y del gobierno se convertían al catolicismo, dejando a un lado su tradicional práctica protestante. Ver Price, 1954:32.

${ }^{16}$ Debido al incendio ocurrido a la intendencia hacia finales de 1970, se perdieron muchos datos y documentos de propiedades de tierra en la isla. Este todavía es un episodio doloroso para algunos miembros de la población raizal quienes población raizal, quienes considera fueron despojados de sus propiedades a causa de este incendio. En los últimos años, tanto en esta población como en la academia se están realizando esfuerzos para recuperar la memoria para recuperare la memoria rialidades ancestrales, por un lado para comprender la magnitud del proceso de expropiación de tierras y por otro, con el fin de declarar la propiedad colectiva del pueblo raizal y de recuperación de toponimia local Las instituciones que lideran este proceso son la Gobernación Departamental, CORALINA $\mathrm{y}$ en estos momentos en el marco de la Maestría en Estudios del Caribe, se está realizando una investigación sobre territorialidades, bajo labre teción Francisco Avella, sociólogo, docente de la Sede Caribe de la Universidad Nacional de Colombia. 
${ }^{17}$ Este barrio debe su nombre, debido a que allí se encuentra la elevación más alta de la isla. También se reconoce porque se cree que es uno de los sectores de mayor peligrosidad de la isla, donde habitan varios jóvenes integrantes de pandillas que se enfrentan con jóvenes de otros barrios aled ños, en situaciones similares, como el cocal o Cartagena Alegre.
Por citar un ejemplo de lo anterior, se encuentra el caso de los asentamiento realizados alrededor de lo que hoy se conoce como el barrio el Cliff ${ }^{17}$. Según algunos habitantes de los alrededores de este barrio, se cree que muchos de los habitantes que lo construyeron provenían de sectores marginales y pobres del departamento de Bolívar, del barrio Olaya de Cartagena, sector reconocido en esta ciudad por su condición de pobreza, marginalidad y peligrosidad.

A principios de los años 80, ya se comenzaba a visualizar la complicada situación de desplazamiento de la población nativa raizal, sobre todo de la vida política y cultural de las islas. Sin embargo, el modelo económico de Puerto Libre todavía funcionaba bien, que sumado a la problemática del narcotráfico y las grandes inversiones que se hicieron provenientes de estos recursos, fue poca la atención que llamó esta situación, e incluso aumentaron las migraciones producto de la expectativa que esto generaba. Aunque a nivel político, si se dieron discusiones que se centraron más en la recuperación de la participación política de la población nativa y de sus prácticas tradicionales.

En el marco de este boom económico y político, y bajo el gobierno de Simón González, se desarrollan actividades como el Green Moon Festival y se inicia todo un proceso de movilidad política para asegurar que los dirigentes de las islas sean isleños. De esta etapa surgen personajes representativos como Kent Francis, Samuel Robinson, Fidel Corpus, Julio Gallardo, Juvencio Gallardo, María Teresa Uribe, entre otros, que hasta hoy día son voceros y representantes políticos de la población isleña, algunos con más poder y vigencia que otros.

Debido en gran medida a las presiones de sectores y representantes nativos, se incorpora a la Constitución de 1991, las reglamentaciones especiales para el Archipiélago y se eleva este a la categoría de departamento. Estas normas a la luz de la visibilidad política y recuperación cultural, se consideró el marco ideal para el mejoramiento de la condiciones de los raizales en las islas. Sin embargo, la situación de multietnicidad del territorio en San Andrés, sumado a que el desarrollo económico de la isla estaba en manos de inversionistas extranjeros y que los gobiernos locales, si bien eran raizales, no tenían el suficiente poder decisorio y de gestión, en ocasiones por corrupción y en otras por falta de competencias del ente territorial con relación al nacional, poco fue lo que se aplicó y se puso en funcionamiento del nuevo marco normativo. Por el contrario, el naciente departamento, se declaró en ley 550 que cobijaba a los entes territoriales declarados en quiebra. 
Para el año de 1993, con la declaratoria de apertura económica del país, se cayó el modelo económico del Puerto Libre, esto, sumado a la quiebra del departamento, principal empleador de la población raizal, y los efectos sociales de crecimiento poblacional y de la pobreza y violencia social producto de las migraciones discriminadas y de la presencia del narcotráfico en la isla, hacen que se incremente en la población isleña la percepción de deterioro y amenaza de la viabilidad y sostenibilidad ambiental de la isla. Los raizales, también se sintieron amenazados, debido a que con la quiebra y reestructuración de la gobernación muchos quedaron sin empleos y con dificultades económicas, aumentando su condición de vulnerabilidad social y cultural. En este contexto se inicia una fase, en la sociedad isleña, de la reivindicación raizal, a través del liderazgo de los grupos religiosos, que promulgan la autonomía y autodeterminación del pueblo desde los púlpitos y las marchas y protestas pacíficas.

Estas acciones y discursos reivindicatorios, han traído como consecuencia una nueva conciencia de lo raizal, pero también han generado polémica por la forma en que estos ven sus relaciones con el gobierno nacional y con el resto de la población isleña de origen no raizal o de situación de inmigrante. Dentro de estos discursos, el que más fuerza ha tomado por su carácter organizativo es el del grupo separatista AMEN SD, posición no compartida por toda la comunidad raizal, pero que dejó una sensación de vulnerabilidad social a la población de la isla no perteneciente a la comunidad raizal. Debido a la fuerza de esta tendencia organizativa y política, de considerar como válidos los argumentos acerca de sus derechos sobre el territorio insular y de que son ellos los únicos llamados a ser los isleños.

\section{Discursos en torno a las identidades socioculturales en San Andrés Isla.}

Del análisis de los discursos sobre la situación sociocultural de la isla, se encontró que si bien el gobierno nacional, expresado en la normatividad especial para el Archipiélago y la población raizal, resalta los valores culturales y los derechos territoriales de los raizales, este nunca menciona ni crea leyes excluyentes para los migrantes ni para los hijos de estos. Por el contrario, en el decreto 2760 que da origen a la oficina de la OCCRE, da a entender como los isleños no raizales nunca pierden su derecho a la residencia y no estipula reglamentación distinta para ellos, aunque nunca deja claro si tienen condición de nativos o no. 
${ }_{18} \mathrm{Al}$ respecto ver los trabajos de: VALENCIA, Inge. El Movimiento raizal: Una aproximación a la identidad raizal a través de sus expresiones político-organizativas. Trabajo de grado para optar al título de antropóloga. Universidad Nacional de Co-

Una

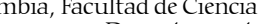
Humanas, Departament de Antropología, Sede Bogotá.2002,. y GUEVARA, N. (2005). "Entre Colombia y el Caribe: Movimiento Autonomista en San Andrés Isla". Trabajo de grado. Fac. De Antropología, Universidad Nacional de Colombia. Sede Bogotá.2005.
Otro aspecto significativo del discurso nacional, es que los raizales hacen parte de las denominadas comunidades negras o afrodescendientes y los nuevos planes de acción para estos, están en el mismo nivel que los que realizan para la población afrocolombiana del Pacífico colombiano o para los palanqueros, situación que no es compartida por todos los representantes de la comunidad raizal, que aspiran a ser reconocidos como "pueblo indígena raizal" y tener más posibilidades de autodeterminación y autogobierno, similar a lo que ocurre con los entes territoriales indígenas.

Por otro lado, al analizar el Plan de Desarrollo formulado por la Gobernación Departamental, para el periodo 2008- 2011, se puede apreciar que el discurso del gobierno local por su parte, sin promover la exclusión y reconociendo la coexistencia de otros grupos étnicos y culturales en la isla, tiene unas políticas y acciones claras de reconocimiento y protección a la etnia raizal en el marco de la normatividad colombiana. A pesar de esto, estas políticas no han sido asumidas con total agrado por la población raizal, debido a que consideran que éstas se quedan cortas en los logros y que lo que propone no es suficiente para las necesidades de esta población.

En los discursos académicos por su lado, se observa como inicialmente los estudios sobre las islas trataban sobre los aspectos históricos de estas y sus dinámicas de poblamiento, hasta culminar con el análisis de los efectos del Puerto Libre en la población isleña. Después de la Constitución de 1991, estos discursos académicos comienzan el proceso de "etnización" de lo raizal y se enfocan a documentar a la luz de las normatividades, sobre la raizalidad e incluso algunos describen que es y que no es lo raizal. A partir de las protestas de los raizales y de la percepción de conflicto latente del contexto insular (Avella, 2000), se inician una serie de investigaciones que cuestionan el carácter cultural de la etnicidad raizal ${ }^{18}$ y que analizan el carácter político bajo el cual se ha fortalecido la etnicidad y como este ha sido uno de los principales fuentes de conflicto entre los actores sociales (Polanía, 2005). Estos discursos avanzan en el análisis de los efectos de la "etnización" en la convivencia de la población insular y dan cuenta de cómo esto puede ocasionar conflictos de otras dimensiones a lo discursivo entre los actores sociales. Sin embargo, se considera que estos estudios poco avanzan en la mirada de que los "otros" no raizales, también se consideran actores activos y reclaman también unos derechos territoriales y culturales con el territorio insular.

Como una forma de mostrar a los "otros" o a los "invisibilizados" se desarrollan dos investigaciones significativas que avanzan en los discursos que en la isla 
a partir de las migraciones generadas del Puerto Libre, se han constituido en nuevas formas en la sociedad isleña, que podrían ser tan válidas como las que defienden los grupos raizales. González (2003), al respecto, señala como se ha dado un proceso de identificación con los valores insulares de la población migrante situada en los barrios de Morris Landis y Ciudad Paraíso, pero además llama también la atención sobre las territoriales que estos han construido en sus barrios y los significados que cobran para ellos, que hace que superen su condición de migrantes.

Por su parte, Ramírez (2005) analiza la situación de los jóvenes isleños, y concluye como para estos hay aspectos que están influenciando más en sus identidades juveniles que las tradicionales categorías sociales, el gran avance de estos discursos es que comenzó a nombrar y resaltar la condición de isleños de los hijos de migrantes nacidos en la isla. Y para finalizar estos discursos, García (2010) problematiza en su tesis de magíster, la condición de hibridez de los denominados fifty- fifty y el carácter que esta condición toma en medio del conflicto interétnico; esta autora concluye como hay una fuerte tendencia entre los mestizos a negar esta condición, con tal de ser reconocidos y aceptados dentro de la etnia raizal.

Con relación a los discursos de las organizaciones raizales ${ }^{19}$, se concluye que hay dos grandes tendencias, una hacia la separación del pueblo raizal de los valores de la nación colombiana, mientras que la otra, sigue en su esfuerzo de resaltar los valores de la etnia y fortalecerlo ante los organismos nacionales y locales, buscando una posición de privilegio y poder de estos con respecto a los demás grupos culturales que cohabitan en el territorio insular. Una conclusión similar, se pudo apreciar de los discursos de los actores sociales entrevistados, mientras que aquellos que pertenecen a los grupos separatistas, tienen una postura radical con respecto a la situación de la isla, los otros actores, raizales que viven fuera de la isla y no raizales, reconocen la importancia de preservar los valores y tradiciones de la cultura raizal por encima de los otros grupos culturales y, hacen un llamado a la coexistencia pacífica y a la superación de las dificultades por la vía política.

\section{¿Raizales, "pañas", fifty- fifty, "turcos" o isleños?: Resultados encontrados en las historias de vida}

Para finalizar, los dos últimos objetivos de la investigación que tenía como finalidad analizar, la forma en que los nuevos isleños constituían sus

19 Para el análisis de los discursos de las organizaciones sociales, se tomó como referencia dos grupos: el primero de ellos fue el grupo AMEN-SD y el otro fue el de ORFA (Orgatro ción de Raizales Residentes cor por Fuera del Archipiélago) quienes tienen su sede principal en la ciudad Bogotá. El análisis que se realizó en esta investigación, tomo como referencia las entrevistas realizadas a algunos de sus líderes, documentos de las organizaciones y las presentaciones realizadas en el marco del seminario sobre normatividad étnica realizado por la Gobernación Departamental el 10 y 11 de Septiembre de 2010 en la Caja de Compensación Familiar, CAJASAI en la Isla.

Palobra No. 11. Septiembre de 2009 - Agosto de 2010 
identidades socioculturales y si estos daban cuenta o no de identificaciones con alguno de estos procesos, o de su pertenencia étnica o si por el contrario obedecía o era producto de las prácticas cotidianas surgidas de la condición de insularidad, sobre todo teniendo en cuenta que el excesivo énfasis que se da a los isleños raizales, podría estar invisibilizando las otras formas de constituirse en un isleño sanandresano.

De lo anterior, las historias de vida documentadas mostraron, que si bien la variable étnica es importante para las expresiones culturales, estas no son tan determinantes en la construcción identitaria de los isleños jóvenes, como si lo es el peso de los discursos en torno a estas y las prácticas cotidianas. Es decir, algunos jóvenes se llaman raizales, "pañas" o árabes a sí mismo, más que por considerarse como tal, es porque otros los llaman así y por condicionamiento social han asumido esta forma de denominarse sin que necesariamente estén de acuerdo con estas formas, lo que se observa sobre todo en los hijos de los migrantes. Los isleños hijos de raizales y los fifty-fifty consideran como un símbolo de orgullo llamarse a sí mismos raizales, debido a las significaciones sociales y políticas que esta categoría encierra. A pesar del peso de los discursos, tanto unos como otros se consideran isleños, solo que las identificaciones socioculturales de los hijos de migrantes se constituye de manera diferente.

Un caso a resaltar de lo anterior, es que entre estos isleños hijos de migrantes, también se resalta adicional a la identidad insular, los valores de la nación colombiana y de la región de la que provienen sus familias, lo que marca diferencias significativas entre los que vienen de una región y otra del continente colombiano. La diferencia más notoria es la que se observa entre los que desciende de la zona andina y los de la costa Caribe colombiana, mientras que la colonia paisa es reconocida dentro del sector económico y de clase alta en la isla, los de origen costeño se asocian más como la mano de obra del sector hotelero y turístico.

Por lo anterior, describir con más exactitud las identidades de los isleños de origen "paña", requiere de un estudio más profundo al respecto ya que estas son tan complejas porque dependen no solo de la región de la que provienen, también influyen factores como el departamento e incluso la ciudad o el barrio del que provienen sus familias. Otra variable que influye es el tiempo que lleva la familia de residencia en la isla, lo cual se expresa en que las familias que más tiempo llevan viviendo aquí, se asumen más fácilmente como isleños que las otras que provienen de migraciones más recientes. 
Por su lado, los sirios- libaneses y judíos que sus familias tienen origen en el país, se consideran tan colombianos, como cualquiera de los otros dos grupos. Solo que para ellos la variable religiosa y pertenencia étnica es la que más resaltan en sus identidades. Además de que no se debe olvidar el carácter transnacional de estos, que hace que aunque tengan muchos años de residencia en un país o territorio, si las condiciones económicas cambian o son adversas, fácilmente migran a otros territorios que se perciban más prometedores, para el caso de la isla, muchas nuevas familias han llegado y otras han migrado para Panamá. A pesar de esto, se concluye que estos grupos con religiones, lengua y costumbre propias, valdría la pena estudiarse dentro de las categorías de grupos étnicos minoritarios del país.

Para finalizar, se considera que el verdadero foco de conflicto identitario en el territorio insular, se está dando por parte de los grupos de jóvenes raizales y de los jóvenes isleños mestizos. Debido a que la radicalización en los discursos en torno a lo que es y no es ser raizal está generando, para el caso de los primeros, un conflicto identitario que hace que algunos que no cumplan con estas características consideren que no hacen parte de la etnia o no son aceptados por esta. Para el caso de los isleños mestizos, la categoría fifty- fifty o half and half, no es reconocida como una categoría social, ni étnica, por la normatividad para la isla. Lo que señala la norma, es que si estos logran comprobar su descendencia del grupo raizal, se asumen como tal, es decir a la luz de la norma sobre pertenecía étnica éstos serian raizal. El conflicto identitario para ellos estaría en la medida en que en las prácticas cotidianas se les cuestione a estos su pertenencia étnica, por ser producto de un proceso de mestizaje, o se les pide que asuman su identidad y pertenencia al grupo raizal por encima de la otra.

Sin embargo, y para finalizar, se considera que los mestizos, debido en gran medida por los procesos de transculturación y prácticas cotidianas, son la tendencia en el crecimiento de la población isleña en general y de la raizal en específico, es decir, que muchos de los llamados raizales, en próximas generaciones, serán producto de mezclas de este grupo con población perteneciente a los otros grupos culturales.

\section{Conclusiones}

Después de realizada la investigación, que abarcó la dinámica de construcción identitaria de la población que habitaba la isla de San Andrés desde su primera colonización, hasta la situación actual, se puede concluir en primer lugar, que

Palubra No. 11. Septiembre de 2009 - Agosto de 2010 
el análisis de las dinámicas geopolíticas y de poblamiento del Archipiélago muestran como este, ha estado a lo largo de su historia marcado por constantes cambios de población, desde que se estableció la primera colonia inglesa puritana en la isla hasta inicios del siglo XX, que marcó el carácter diverso de la población isleña que se constituye en lo que hoy día es conocido como la comunidad o pueblo raizal. Esto no indica que no se deban considerar como grupo primario de las islas, por el contrario, lo que se quiere señalar, en la dificultad misma que habría para definir qué es ser raizal y que no lo es, más allá del demostrar su residencia en la isla antes de la declaratoria del Puerto Libre. Sin negar que hay unas prácticas culturales asociadas a la mayoría de los pertenecientes a esta población, pero que no eran compartidas por todos ellos, sobre todo después de las políticas intervencionistas del estado colombiano puestas en marcha con mayor fuerza a partir de 1926 con la llegada de misioneros capuchinos a las islas.

Con relación a los discursos sobre las identidades culturales en la isla, se pudo comprender de las entrevistas realizadas y documentos analizados, que muchos de los discursos sobre la etnicidad y la identidad cultural en la isla, se dan más por las problemáticas de tipo ambiental, social, económicas, de seguridad y política que están afectando la calidad de vida de todos los pobladores en mayor o menor grado, y que están asociadas a la llamada "situación de sobrepoblación de la isla generada en su primer momento por migraciones descontroladas", que por un conflicto cultural, producto de la convivencia de distintos grupos culturales en la isla. Lo que se presume que está ocurriendo en San Andrés es que a falta de mayores discursos para comprender la situación de crisis de la isla y de acciones para sus posibles salidas, se está utilizando la bandera de las identidades étnicas y culturales como "caballo de batalla", sin ser esta realmente la causa de la situación actual de las islas. Sin embargo, se considera que llegará el día en que este discurso no será suficiente para tapar la complejidad de la situación insular, que requiere de urgentes medidas de intervención del gobierno y de todos aquellos que por nacimiento, vocación o adscripción se hacen llamar isleños.

Como conclusión final, se considera que con relación a las prácticas culturales, independiente de la pertenencia étnica y la situación especial de la isla, la tendencia mundial es la hibridación cultural, debido en gran medida al proceso de globalización que está llegando a todas las esferas del planeta tierra y las islas no están por fuera de ello. Por lo anterior, se recomienda que, en vez de cuestionar las otras prácticas culturales distintas a las de la población raizal, 
se promuevan espacios y escenarios de promoción de las prácticas culturales y artísticas raizales que hagan que nazca en los jóvenes isleños, raizales y no raizales, la necesidad y el deseo de conservarlas.

\section{BIBLIOGRAFIA}

AVELLA, Francisco. (2000). "Conflictualidad latente y convivencia abierta, el caso de San Andrés". En: La Universidad piensa la paz: obstáculos y posibilidades. Bogotá: Universidad Nacional de Colombia, programa de iniciativas universitarias para la paz y la convivencia (PIUPC).

BARTH, Frederick, (1969) Los grupos étnicos y sus fronteras: la organización social de las diferencias culturales. México: Fondo de Cultura Económica.

CLEMENTE, Isabel. (1994) "El Caribe Insular: San Andrés y Providencia" En: Meisel, Roca (ed). Historia Económica y Social del Caribe colombiano. Bogotá. Págs. 331-372.

GARCIA, Sally. (2010) Los "half \& half o fifty fifties" de San Andrés los actores invisibles de la raizalidad. Trabajo de grado Magíster en Estudios de Caribe. San Andrés Isla: Universidad Nacional de Colombia, Instituto de Estudios Caribeños.

GAVIRIA, Enrique. (1984). Complemento de la historia de Colombia: Nuestro Archipiélago de San Andrés y la Costa Mosquitia. Colombiana. Bogotá: Plaza y Janes. Academia colombiana de Historia.

GONZÁLEZ, Gabriel. (2003). “Los nuevos pañamanes: procesos identitarios y apropiación del espacio por el continente migrante en la isla de San Andrés. Caribe colombiano". Tesis de grado, Fac. de antropología. Bogotá: Universidad Nacional de Colombia.

GUEVARA, Natalia. (2005). "Entre Colombia y el Caribe: Movimiento Autonomista en San Andrés Isla". Trabajo de grado. Fac. de Antropología. Bogotá: Universidad Nacional de Colombia.

HALL, Stuart. (1985). "Etnicidad, identidad y diferencia". En: Revista de estudiantes de sociología, traducido por Eduardo Restrepo. Bogotá: Universidad Nacional de Colombia.

LOSZONCY, Anne- Marie, (1997)"Hacia una antropología de lo interétnico. Una perspectiva negroamericana e indígena". En: Uribe, María y Restrepo, Eduardo. Antropología en la modernidad: Identidades, etnicidades y movimientos sociales en Colombia. Instituto Colombiano de Antropología, Bogotá, Págs., 253-278.

MEISEL, Adolfo. (2003). La continentalización de la isla de San Andrés, Colombia: Panyas, raizales y turismo, 1953-2003. Documentos de trabajo sobre economía regional. Centro de estudios económicos regionales. Cartagena: Banco de la República.

MINTZ, S. (1971). "The caribbean as a social-cultural area". En: Harwitz, Michael, ed.

Palubra No. 11. Septiembre de 2009 - Agosto de 2010 
Peoples and cultures of the Caribbean: Anthropological reader Garden City. New York Natural History Press. Págs.17-46.

MITCHELL, Dulph, (2010) Análisis de los motivos para las exigencias de Autodeterminación del Pueblo Raizal ante los Organismos Internacionales OAS y ONU. Conferencia presentada en el marco del seminario sobre normatividad étnica. Septiembre. (Documento inédito).

MORENO, Manuel. (1999) "En torno a la identidad cultural en el Caribe Insular". En: La historia como arma y otros estudios sobre esclavos, ingenios y plantaciones. Barcelona: Romayá/Valls, Capellades. Págs. 162-171.

. (1996) "Aportes culturales y deculturación". En: Pérez Esther y Lueiro, Marcel (Comp.). (2009) Antología de caminos: Raza y Racismo. Ciudad de la Habana (Cuba): Editorial Caminos. Págs. 22- 47.

NEWTON, Arthur Percival. [1914] (1985). Providencia: las actividades colonizadoras de los puritanos ingleses. Bogotá: Banco de la República.

PARSONS, James J. [1956] (1985). San Andrés y Providencia: Una Geografía Histórica de las Islas Colombianas del Caribe. Bogotá: El Ancora Editores.

PRICE, Thomas J. 1954. "Algunos aspectos de estabilidad y desorganización cultural en una comunidad isleña del Caribe Colombiano". En: Revista Colombiana de Antropología. Bogotá. Vol. 3, Págs. 11-54.

POLANÍA, María Fernanda (2005). Normatividad y conflicto intercultural en San Andrés isla, Caribe colombiano. Trabajo de grado Magíster en Estudios de Caribe. San Andrés Isla: Universidad Nacional de Colombia. Instituto de Estudios Caribeños.

PUSEY, Enrique. (2003) "Los Sucesivos Reclamos de Nicaragua". En: Revista Islander, Bilingual Magazine. Núm. 14. San Andrés.

RAMÍREZ, Lorna. (2005) ¿Gomelos, champes o normales? Representaciones de las identidades juveniles en San Andrés isla. Trabajo de grado Fac. Antropología. Bogotá: Universidad Nacional de Colombia.

RAMÍREZ, Socorro. Y, Luis. (2003) Cuadernos del Caribe No4, Textos y testimonios del archipiélago; crisis y convivencia en un territorio Insular. Universidad Nacional de Colombia Sede Caribe. San Andrés Islas, Colombia.

RATTER, Beate. [1992] (2001). Redes Caribes. San Andrés y Providencia y las islas Cayman: entre la integración económica mundial y la autonomía cultural regional. Bogotá. Instituto de Estudios Caribeños. Universidad Nacional de Colombia.

República de Colombia. (1991). Decreto ley 2760. Bogotá.

República de Colombia. (1999). Decreto 2548. Bogotá.

República de Colombia. (1993). Ley 47. Bogotá. 
República de Colombia. (1993). Ley 70. Bogotá.

RESTREPO, Eduardo. (2007). Identidades planteamientos teóricos y sugerencias metodológicas para su estudio. En: Jangwa Pana, $N^{\circ}$ 5. Santa Marta: Universidad del Magdalena.

SANDOVAL, Carlos. (1996). Investigación cualitativa. Bogotá: Instituto Colombiano para el Fomento de la Educación Superior, ICFES.

SANDNER, Gerhard. [1984] (2003). Centroamérica y el Caribe occidental. Coyunturas, crisis y conflictos 1503-1984. Universidad Nacional de Colombia. Bogotá: Instituto de Estudios Caribeños. Universidad Nacional de Colombia.

URIBE. Diego. (1986). Libro blanco de la República de Colombia. Bogotá: Ministerio de Relaciones Exteriores.

VALENCIA, Inge. (2002). El Movimiento raizal: Una aproximación a la identidad raizal a través de sus expresiones político- organizativas. Trabajo de grado Fac. Antropología. Bogotá: Universidad Nacional de Colombia.

VOLLMER, Loraine. (1997). La historia del poblamiento del Archipiélago de San Andrés, vieja Providencia y Santa Catalina. San Andrés Islas: Ediciones Archipiélago.

\section{CIBERGRAFIA}

AMEN-SD (2007) "185 años de colonialismo interno (1822-2007)". En: Pagina web de la Organización AMEN- SD. www.amen-sd.org. Fecha de consulta: 20 de agosto de 2009.

DANE. (2009) Registro de población y vivienda censo de 2005 En: Pagina web www. dane.gov.co. Fecha de consulta: 20 de agosto de 2009.

Departamento Archipiélago de San Andrés, Providencia y Santa Catalina. En: Pagina web www.gobernacionsai.gov.co. Fecha de consulta: 28 de agosto de 2009. 